\title{
CADMIUM AND HYPERTENSION IN EXPOSED WORKERS: A META-ANALYSIS
}

\section{TIZIANA CACIARI ${ }^{1}$, ANGELA SANCINI ${ }^{1}$, MARIO FIORAVANTI ${ }^{2}$, ASSUNTA CAPOZZELLA ${ }^{1}$, TEODORICO CASALE ${ }^{1}$, LUCIO MONTUORI ${ }^{1}$, MARIA FIASCHETTI ${ }^{1}$, MARIA PIA SCHIFANO ${ }^{1}$, GIORGIA ANDREOZZI ${ }^{1}$, NADIA NARDONE ${ }^{1}$, GIANFRANCO TOMEI ${ }^{2}$, MANUELA CIARROCCA ${ }^{1}$, MARIA VALERIA ROSATI ${ }^{1}$, and FRANCESCO TOMEI ${ }^{1}$}

${ }^{1}$ University of Rome 'Sapienza', Rome, Italy

Department of Anatomy, Histology, Medical-Legal and the Orthopaedics, Unit of Occupational Medicine

${ }^{2}$ University of Rome 'Sapienza', Rome, Italy

Department of Psychiatric and Psychological Science

\begin{abstract}
Objectives: In the general population, cadmium seems to be responsible for hypertension, atherosclerosis and an increase in acute coronary events. Therefore, the purpose of this meta-analysis was to analyze controlled studies conducted on cadmium and arterial pressure in occupationally-exposed workers. Materials and Methods: After analyzing all the relevant articles found in the literature, 6 publications were selected. Results: A higher prevalence of hypertension and higher values of systolic and diastolic blood pressure were recorded in the exposed subjects. Conclusions: Cadmium in occupationallyexposed individuals appears to induce an increase in systolic and diastolic blood pressure and an increase in the prevalence of hypertension.
\end{abstract}

Key words:

Cadmium, Hypertension, Cardiovascular disease, Workers, Meta-analysis

\section{INTRODUCTION}

Cadmium is a ubiquitous pollutant in the living environment. The three main sources of exposure to cadmium in the general population are diet (it is found in several food types such as shellfish and organs [1]), smoke (it is a source of on average 10-15 $\mu \mathrm{g}$ per day), and atmospheric pollution (personal average absorption of cadmium due to pollution has been estimated at $0.5 \mu \mathrm{g} / \mathrm{m}^{3}$ for populations residing in areas with a high level of urbanization) [2]. Moreover, it is found in small quantities i.e. less than $0.1 \mu \mathrm{g} / \mathrm{l}$, in drinking water [3].
Exposure to cadmium and its components (cadmium oxide, cadmium sulphate, cadmium sulphide, cadmium chloride and others) also occurs in the work environment, where it is used for many purposes. It is mainly used in production of nickel-cadmium alkaline batteries (80\%) [4], in production of pigments for paints (10\%) (Landrigan, 1982), in mining, cadmium forging [5], in the construction of certain semi-conductors, in electronics, in the field of plastics as a stabilizer (e.g. polyvinyl chloride - PVC), as well as in the production of fertilizers. Cadmium recycling

Received: February 7, 2012. Accepted: January 7, 2013

Corresponding author: G. Tomei, Department of Psychiatric and Psychological Science, University of Rome "Sapienza", Piazzale Aldo Moro 5, 00185 Rome, Italy (e-mail: franc.tomei@alice.it). 
is gaining importance as another potential source of poisoning from cadmium and it now represents $10-15 \%$ of total cadmium production [6]. Cadmium penetrates the human body through the principal routes of toxic matter absorption (i.e. through the lungs, gastro-intestinal tract and skin), however, in the case of professional exposure, the amount of cadmium absorption through ingestion and skin is considered to be much less important.

The effects of cadmium on the kidney and lungs are well known. However, the role of cadmium and its derivatives in the induction of cardiovascular diseases seems much more controversial. Over time, several studies have been conducted on the general population, on animals and on cells in vitro. However, the literature concerning professional exposure to cadmium and the onset of cardiovascular pathologies is very limited [7].

Cadmium seems to be the cause of an increased prevalence of peripheral arteriopathies [8], heart failure [9], myocardial infarction [10], hypertension [11] and atherogenic alterations [12]. In a study conducted by Shutte in 2009 [13] on persons residing in two areas of the country with high and low concentrations of cadmium, alterations in femoral compliance and in femoral distensibility were reported in persons with high levels of cadmiuria. In 1989, Hermann [14] did not register higher systolic and diastolic blood pressure values in a group characterized by high exposure to cadmium.

As regards studies on people with cardiovascular diseases (hypertension, coronopathies, myocardial infarction, atherosclerosis) [15], a high concentration of cadmium was found in blood [16], urine [17], scalp [18], hair and nails [19] of the patients suffering from these pathologies. Studies conducted on animals demonstrated specific electrocardiogram alterations (lengthening of the P-R interval) [20], increased prevalence of hypertension [21], atherosclerosis [22], and other cardiovascular pathologies [23], while studies conducted in vitro on human cells, demonstrated how cadmium can induce endothelial alterations
[24], oxidative damage to the cardiac muscle [25] and reduction of coronary flow [26], as well as inhibition of the electron transfer chain within myocytes [27].

As previously mentioned, little research has been conducted in order to explain the role of cadmium and its components in the induction of cardiovascular pathologies in persons exposed as part of their occupation. So far, no meta-analysis on cadmium exposure and the cardiovascular risk in exposed workers has been developed, probably due to the scarcity of appropriate controlled studies. The majority of research conducted on workers in past decades was in fact focused on other types of pathologies, primarily respiratory and renal ones. Many of the studies conducted to clarify the role of cadmium in the development of cardiovascular pathologies did not analyze the workers at the time of exposure to the toxic agent but were post-mortem examinations of their tissues [28-30]. Other researchers, on the other hand, did not include a control group [31], had incomplete data [32] or conducted research of an epidemiological nature [33]. Although the occupational exposure of workers and its effect on their health have been studied [34-39], the influence of cadmium on the cardiovascular system has not been analyzed.

Therefore, the purpose of this study was to summarize and analyze all the controlled studies conducted on cadmium and cardiovascular risks in occupationally-exposed workers by the use of one of the instruments of Evidence Based Medicine, i.e. meta-analysis, in order to understand the effect of this metal on blood pressure.

\section{MATERIALS AND METHODS}

\section{Search strategy}

The meta-analysis was performed by carrying out a systemic search for all articles concerning an evaluation of chronic effects on the cardiovascular system of workers occupationally exposed to cadmium. An extensive search for "cadmium", "cadmium urinary", "blood cadmium", 
"nickel-cadmium battery workers" (or alkaline battery workers), "pigment workers" (or pigment manufacturing plant workers), "cadmium recovery plant", "cadmium electroplating workers" and "hypertension" was performed, using free text and MeSH terms. The papers suitable for inclusion were identified by systematic research on the MEDLINE/Pubmed, TOXNET/Toxline, Biomedcentral, Nioshtic-2, Scopus and EMBASE electronic databases.

The research included articles published between March 1950 and February 2011; unpublished data the authors were aware of, as well as papers from domestic and international conferences in accordance with the indications contained in the Cochrane Handbook for Systematic Reviews (http://www.cochrane-handbook.org). Section 4.7.1 of the Cochrane Handbook for Systematic Reviews of Interventions (http://www.cochrane-handbook.org) reports that any meta-analysis must take into consideration both published as well as unpublished works. This is to avoid errors in the process of selection and inclusion of data, since meta-analysis is acceptable only when it includes all the data available on the topic, whatever their nature or origin.

No restriction was applied with regard to the language or the type of publication.

\section{Study selection and patients}

The study included the following categories of workers: nickel-cadmium battery factory workers, paint/pigment industry workers, ceramic industry workers, metal workers, welders, plating industry workers, workers employed in the disposal of cadmium, as well as farmers.

A systematic search resulted in 454 publications, of which only 47 met the requirements of our study and only 11 were in compliance with the following inclusion criteria (Figure 1):

1. Case-control studies, where the studied group was composed of subjects occupationally exposed to cadmium and a control group of subjects who were not occupationally exposed to cadmium.

2. Studies in which the results were expressed in numerical terms of mean and standard difference or frequency.

Articles which were eliminated basing on the following exclusion criteria (Figure 1):

1. Studies conducted on persons not occupationally exposed to cadmium.

2. Studies conducted on persons with poisoning due to ingestion of cadmium.

3. Reviews, editorials or commentaries without original data.

4. Animal studies without data concerning humans.

5. In vitro studies.

6. Case reports with no control group.

7. No hypertension or blood pressure outcomes.

8. Studies conducted on the effects of environmental pollution with cadmium and with cigarette smoke.

Of the 11 selected works, the final study was excluded, since the control group comprised workers exposed to cadmium pollution [40]. In fact, in this study, a group of workers from an alkaline battery factory was divided into normotensive and hypertensive. Other parameters, such as urinary excretion of cadmium, average age and length of occupational exposure, were also investigated.

Authors of the publications where the full texts was not present were contacted in order to obtain all necessary data to perform the meta-analysis. However, the full texts of four more articles could not be found [41-44], and thus the articles in question were excluded (Figure 1). Finally, a total number of six works was included in the meta-analysis [45-50] (Table 1, Figure 1).

In these six articles, the exposed workers, identified by means of working medical histories, were nickel-cadmium battery factory workers, farmers, those working with pigments and cadmium resins, workers employed in the disposal of cadmium, steel industry workers, and workers in factories producing plastic materials. The control group, 


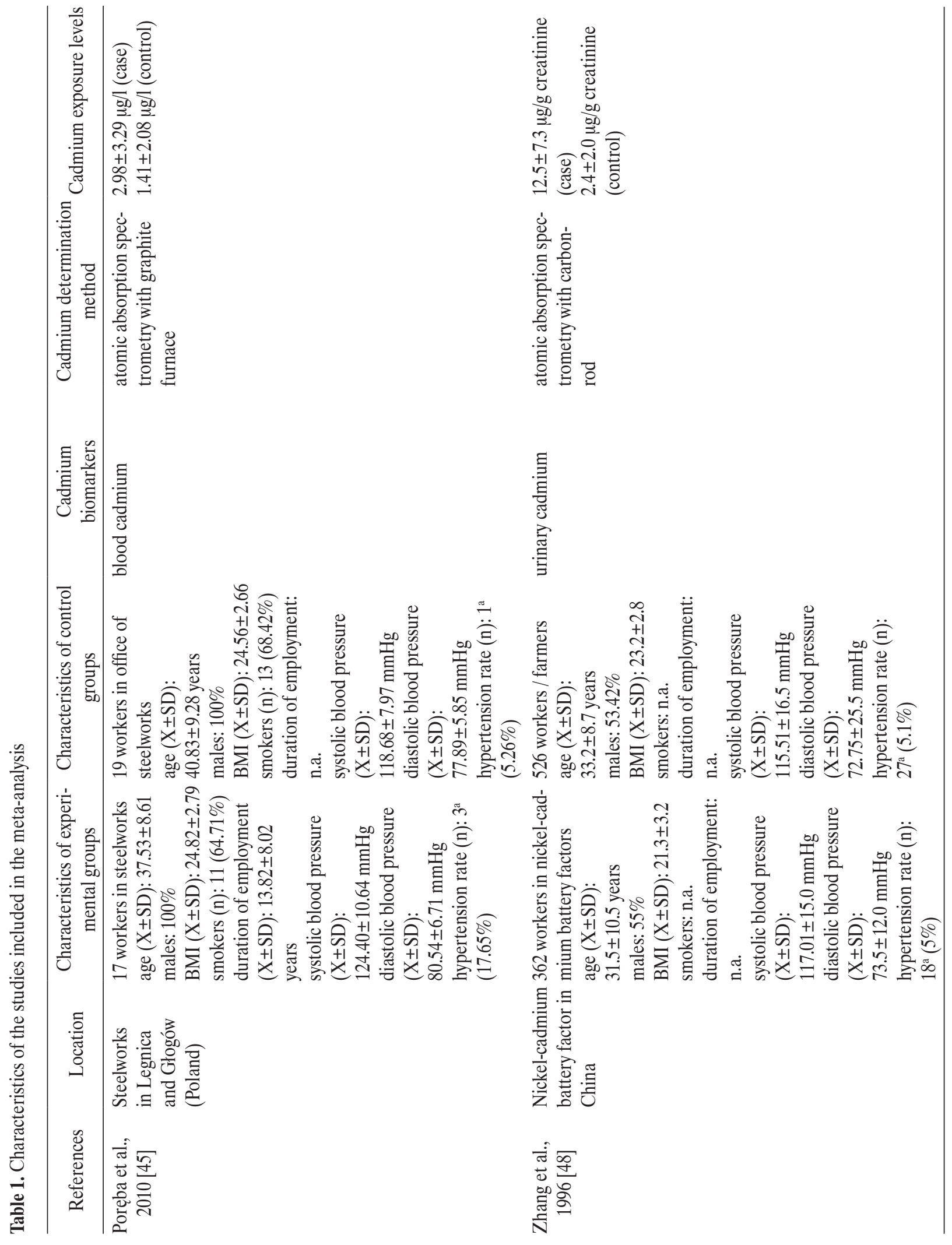




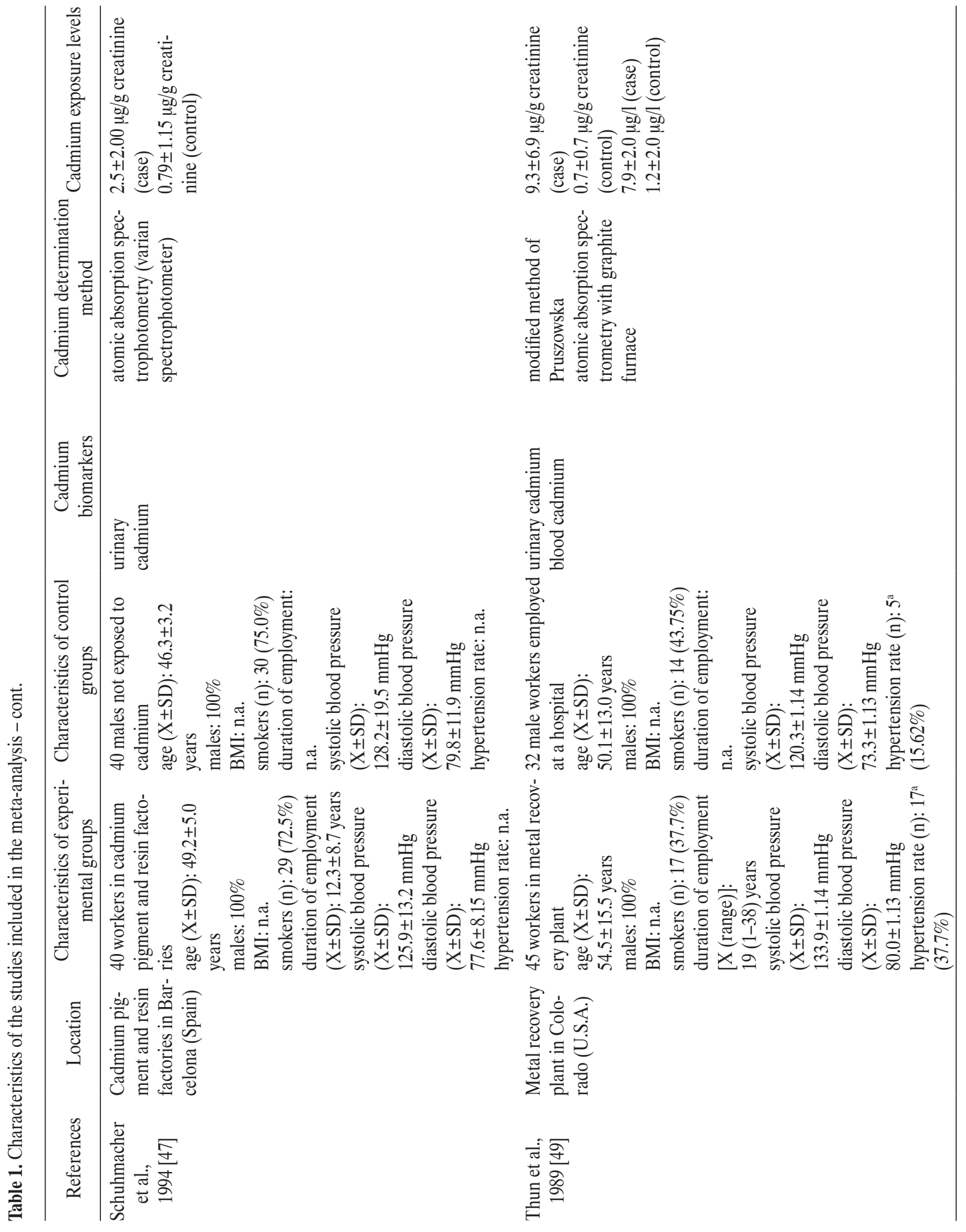




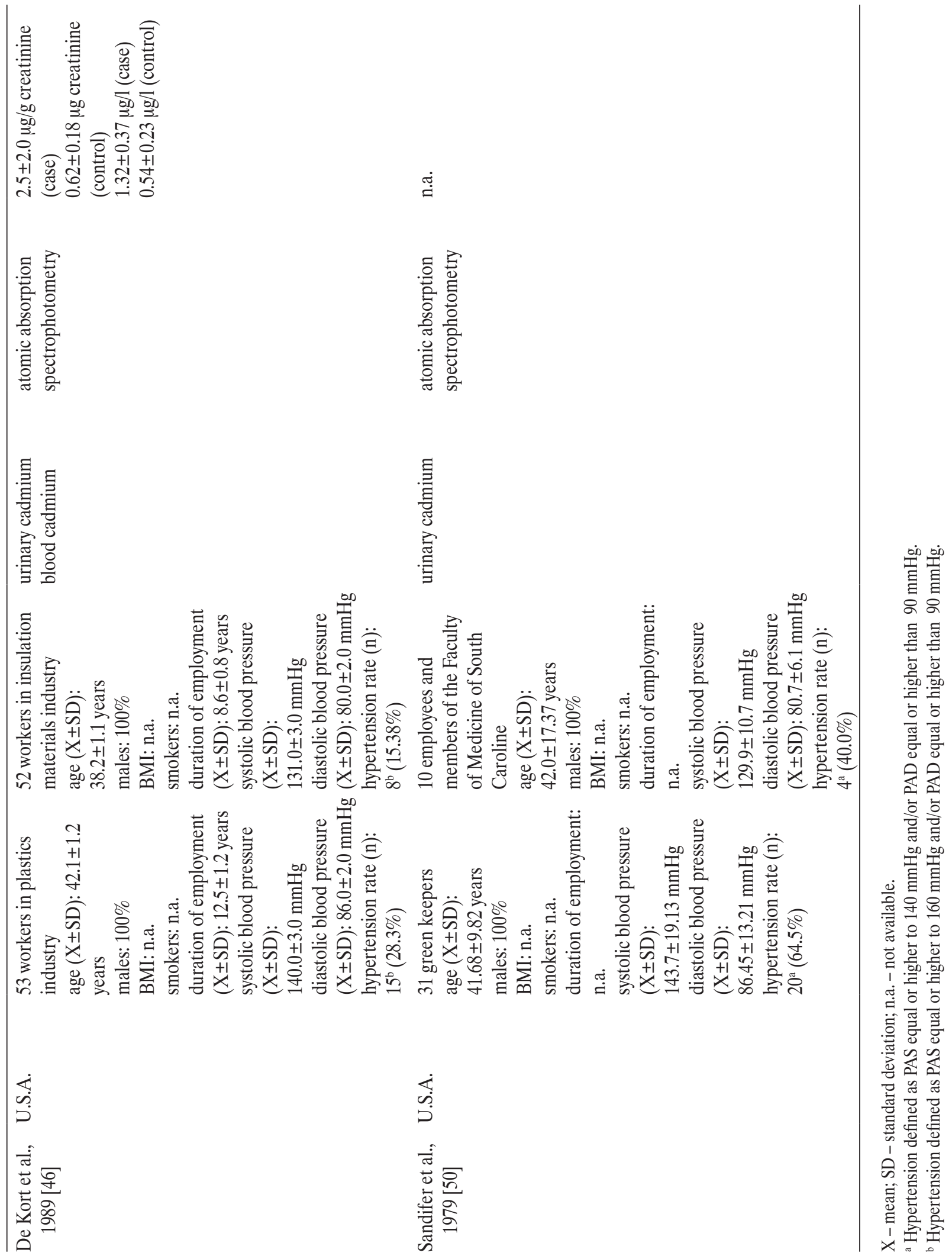


again identified by the use of working medical histories (workers not occupationally exposed to cadmium), was represented by insulation material plant worker, hospital employees, beer factory workers and workers involved in other fields of the industry.

The total number of participants included in the metaanalysis was 1227 . The number of cases was 548, while the number of controls was 679 . The average age of the study group was $42.4 \pm 7.18$, while the average age of the control group was $41.77 \pm 5.43$. The total number of male subjects in the study group was 386 , while the total number of female subjects was 162 ; the total number of male subjects in the control group was 434, while the total number of female subjects was 245 . The number of smokers, identified

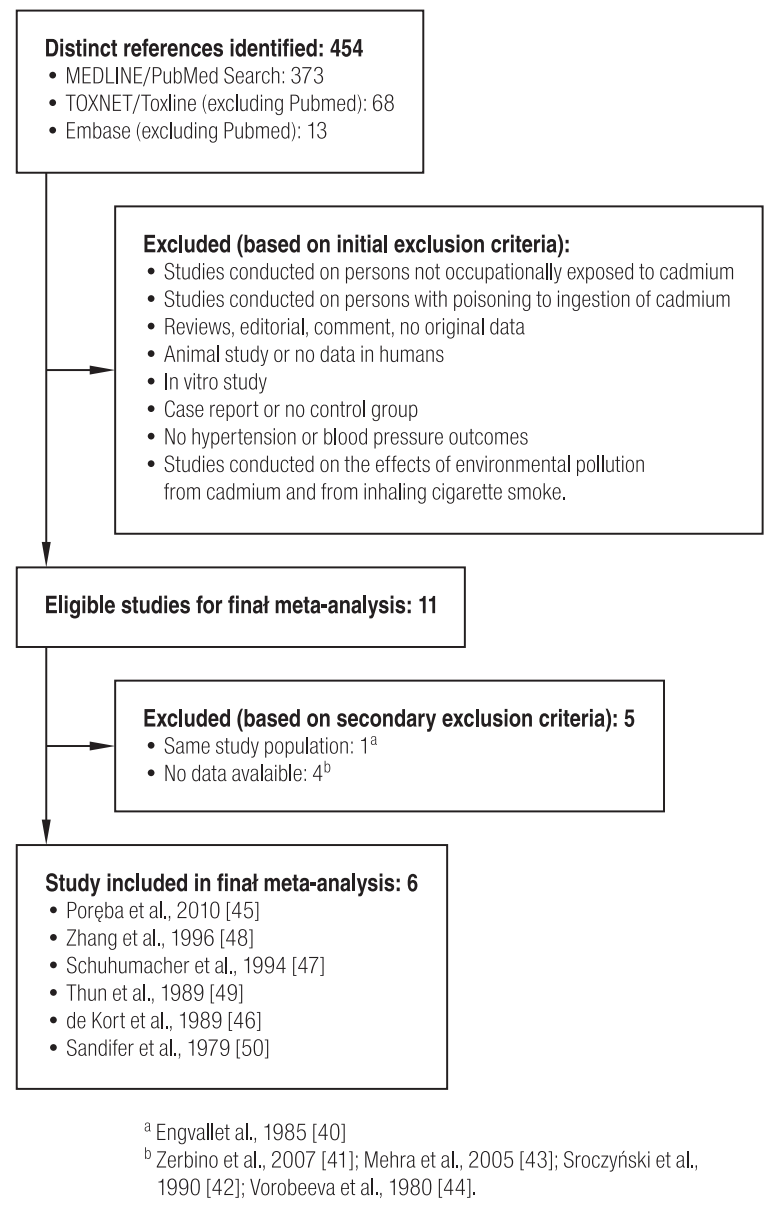

Fig. 1. Flow chart with included/excluded studies with specification of reasons by medical questionnaires, was 57 out of 102 among those exposed to cadmium $(55.88 \%)$ and 57 out of 91 among the controls (62.63\%). Finally, the Body Mass Index (BMI), when data was available, was $23.06 \pm 1.76 \mathrm{~kg} / \mathrm{m}^{2}$ among the exposed workers and $23.88 \pm 0.68 \mathrm{~kg} / \mathrm{m}^{2}$ among the controls. In the examined studies no information concerning the length of service or lipid order was given.

Based on the available data, the results were divided into 3 classes:

- Prevalence of hypertension.

- Values of systolic arterial pressure.

- Values of diastolic arterial pressure.

\section{Measurement}

Systolic and diastolic arterial pressure were measured in $\mathrm{mmHg}$ by the use of an ordinary sphygmomanometer, using respectively phase I and phase $\mathrm{V}$ of the Korotkov tones. Only in one study arterial pressure was measured in kilopascals (Kpa); transformation into $\mathrm{mmHg}$ was conducted in accordance with common methods (1 KPa: $7.5006151 \mathrm{mmHg}$ ).

In cases where prevalence of hypertension was not calculated, it was obtained by correlating the number of hypertensives with the total numbers of the group. A subject was considered hypertensive when his systolic arterial pressure was equal to or higher than $140 \mathrm{mmHg}$, or the diastolic arterial pressure was equal to or higher than $90 \mathrm{mmHg}$, according to the latest guidelines established by the World Health Organization (WHO) [50].

Cadmiemia, which was analyzed in four studies, and obtained by the use of atomic absorption spectrometry with graphite furnace [45-47,49] was expressed in $\mu \mathrm{g} / \mathrm{l}$. However, cadmiuria was expressed in $\mu \mathrm{g} / \mathrm{g}$ of creatinine in three studies: by the use of atomic absorption spectroscopy [46], atomic absorption spectrometry using carbon rods [48] or the modified method of Pruszowska [49]. In the case of one study [50], the values of urinary cadmium were unknown. Ultimately, the available data did not 
allow the limits of detection of cadmiemia and cadmiuria to be tested.

\section{Quality assessment and data extraction}

Two investigators (L.M. and M.F.), independently of each other, screened the titles and abstracts resulting from the search strategies. The articles with titles or abstracts clearly irrelevant were rejected during the first screening. The full texts of potentially relevant articles were reviewed to assess eligibility for the inclusion in the meta-analysis with any disagreement resolved by consensus. All discrepancies were rechecked and the consensus was reached by a third investigator (G.A.).

\section{Statistical analysis}

To express the result of our meta-analysis, the Effect Size (ES), a value which expresses the strength of association between two variables, was used. In addition, the confidence interval, which expresses the precision with which the Effect Size was estimated, was calculated.

Whenever the studies reported data expressed in mean and standard differences, the ES was expressed as Standardized Mean Difference (SMD), which expresses the relationship between the difference of the two means and the assessment of the standard difference within the same group.

The ES was evaluated using the Random Effects Model (REM) - a statistical model in which the confidence interval is influenced both by the error of internal sampling of the study as well as by the variability of the studies included in the meta-analysis. The REM is more reliable since the confidence interval it provides is broader than that provided by the Fixed Effects Model (FEM). As regards ES measurements based on differences, a difference equal to 0.0 indicated a lack of difference among the studied groups.

The Logarithmic Odds Ratio (Log OR) was also calculated between the study and control groups, using regression coefficients. Since the confidence interval corresponded (CI) to $95 \%$ of the observations, the p-value was regarded as $p<0.05$, which expressed the significance of ES. Also in this case, the ES was evaluated using the Random Effects Model (REM). With respect to the ES measures based on relationships such as the OR, a ratio equal to 1.0 indicated the lack of differences among the studied groups.

If the studies reported data expressed in frequency, the ES was expressed as an Odds Ratio (OR). In addition, the ES was evaluated using the Random Effects Model (REM). The Inconsistency Index $\left(\mathrm{I}^{2}\right)$ was used as an indication of heterogeneity. In systematic revisions, heterogeneity refers to the variability or differences among the studies in estimating the effect. $I^{2}$ allowed the percentage of variance to be calculated due to actual heterogeneity rather than chance. If the $\mathrm{I}^{2}$ value is close to zero then the variance observed is due to chance but if the $\mathrm{I}^{2}$ value is high, the variance is attributable to several factors requiring further investigation.

Publication bias was evaluated using funnel plots and by calculating standard errors.

All statistical measures mentioned above were calculated using "Comprehensive Meta-analysis 2.0" software.

\section{RESULTS}

The exposed group and the control group were found to be comparable in terms of age, sex, BMI, and smoking status. In fact, the number of males in the group of exposed workers was 386, while the number of females was 162. In the control group the number of males was 434 , while the number of females was 245 . The average age of cases was $42.4 \pm 7.18$ years, while the average age of the controls was $41.77 \pm 5.43$ years $(p>0.05)$. In the studies where it was specified i.e. [45,47,49], the percentage of smokers in the group of cases was $55.88 \%$, while the percentage of smokers in the control group was $62.63 \%$ 
( $p>0.05)$. BMI, in the studies where it was specified $[45,48]$, was lower among the cases than among the controls $\left(23.06 \pm 1.76 \mathrm{~kg} / \mathrm{m}^{2}\right.$ vs. $\left.23.88 \pm 0.68 \mathrm{~kg} / \mathrm{m}^{2} ; \mathrm{p}<0.05\right)$. As already indicated, the available data enabled a division into 3 classes:

- Prevalence of hypertension.

- Values of systolic arterial pressure.

- Values of diastolic arterial pressure.

\section{Prevalence of hypertension}

The prevalence of hypertension, evaluated in 5 studies (Table 2) on a total sample of 508 cases and 639 controls, was more significant in the subjects occupationally exposed to cadmium than in the control group (Log OR: 1.814; 95\% CI: 1.030-3.196; $p=0.039$, with a value of heterogeneity among the studies equal to $\mathrm{I}^{2} 0.00$ ) (Figure 2).

\section{Systolic arterial pressure}

Systolic arterial pressure, evaluated in 6 studies (Table 2), on a total sample of 558 cases and 679 controls, was more significant in the subjects occupationally exposed to cadmium; the recorded mean systolic blood pressure was in fact higher than $2.325 \mathrm{~mm} \mathrm{Hg}$ compared to the controls (95\% CI: 0.948-3.702; $p=0.001$, with a value of heterogeneity among the studies amounting to $\mathrm{I}^{2}$ 83.65) (Figure 3a). The standard error was 0.702. Log OR between the cases and controls was 4.217 (95\% CI: 1.719-6.714; $p=0.001$ ) (Figure $3 b$ ). The standard error was 1.274.

\section{Diastolic arterial pressure}

Diastolic arterial pressure, evaluated in 6 studies (Table 2), on a total sample of 558 cases and 679 controls, was more significant in the subjects occupationally exposed to cadmium; the recorded mean diastolic blood pressure was higher than $1.548 \mathrm{~mm} \mathrm{Hg}$ in comparison with the controls (95\% CI: 0.284-2.812; $\mathrm{p}=0.016$, with a value of heterogeneity among the studies amounting to
$\left.I^{2} 55.501\right)$ (Figure 4a). The standard error was 0.645. Log OR between the cases and controls was 2.809 (95\% CI: $0.516-5.101 ; p=0.016$ ) (Figure $4 b)$. The standard error was 1.170 .

\section{DISCUSSION}

Cadmium has been associated with cardiovascular disorders since 1950 [52]. Over the years, several studies have been conducted to clarify the role of this ubiquitous metal in the determination of cardio-circulatory disorders. Some studies in the past theorized that accumulation of cadmium in human body could produce an alteration in the metabolism of certain metabolites such as calcium, nickel, zinc [53], selenium and copper. More recently, other authors have demonstrated the influence of cadmium on kidney tissues resulting in the decrease of CYP4A11 and PPARs (peroxisome proliferator-activated receptors), with possible production of hypertension, sodium retention, glucose intolerance, dyslipidemia, and zinc depletion [54]. Other studies have shown that cadmium can cause a loss of molecules with vasodilating functions, such as nitric oxide [55], and it can also increase the effect of norepinephrine [56]. In conclusion, some other authors have demonstrated a cadmium-induced endothelial alteration, which would be mediated by an alteration in the functionality of the M1 acetylcholine receptors [57].

In fact, the endothelial-toxic role of cadmium, has been amply demonstrated by several studies which evidenced its marked role in the constitution of atherosclerotic plaques $[58,59]$. Atherosclerosis, therefore, could be an ulterior factor explaining the hypertensive potential of cadmium. Also determination of hypertension by cadmium in occupational environments could be explained by its accumulation in kidney tissues, which occurs more often in persons chronically exposed to the metal. In the exposed subjects, cadmium can, in fact, cause alterations in the tubular 


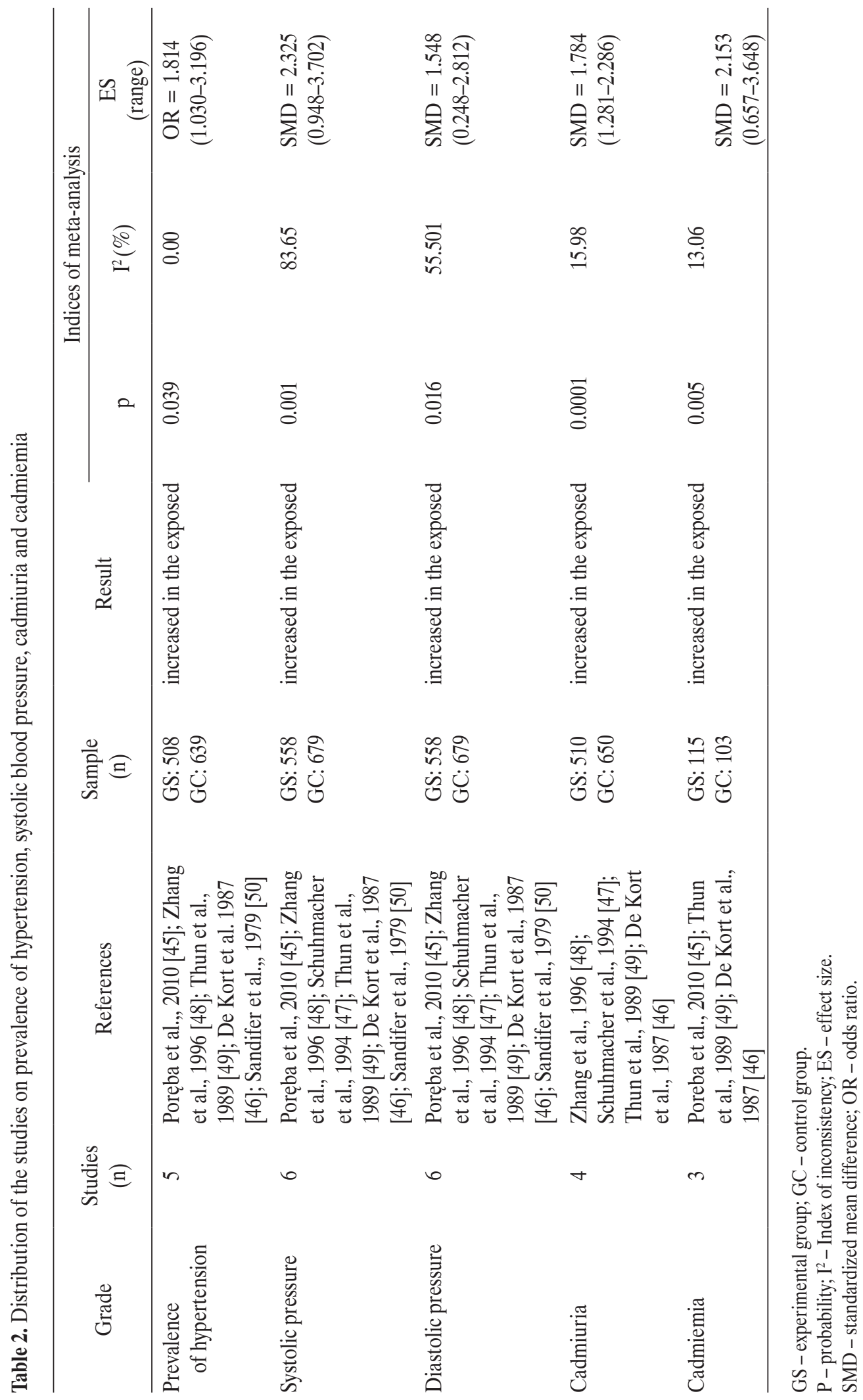




\begin{tabular}{|c|c|c|c|c|c|c|}
\hline \multirow[b]{2}{*}{ Study name } & \multirow[b]{2}{*}{ Comparison } & \multicolumn{5}{|c|}{ Statistics for each study } \\
\hline & & odds ratio & $\begin{array}{l}\text { lower } \\
\text { limit }\end{array}$ & $\begin{array}{c}\text { upper } \\
\text { limit }\end{array}$ & Z-value & $\mathrm{p}$-value \\
\hline Thun et al., 1989 [49] & pigment and resin workers vs. control & 3.274 & 1.058 & 10.127 & 2.058 & 0.040 \\
\hline Zhang et al., 1996 [48] & battery workers vs. hospital workers & 0.979 & 0.531 & 1.806 & -0.067 & 0.947 \\
\hline Sandifer et.al., 1979 [50] & green keepers vs. university members & 2.725 & 0.631 & 11.776 & 1.343 & 0.179 \\
\hline Poręba et al., 2010 [45] & smelter workers vs. office workers & 3.894 & 0.361 & 42.031 & 1.120 & 0.263 \\
\hline De Kort et al., 1987 [46] & plastic vs. insulation material workers & 2.185 & 0.834 & 5.723 & 1.591 & 0.112 \\
\hline & & 1.814 & 1.030 & 3.196 & 2.062 & 0.039 \\
\hline
\end{tabular}

Fig. 2. Forest plot of hypertension Rate
Odds ratio and $95 \% \mathrm{CI}$

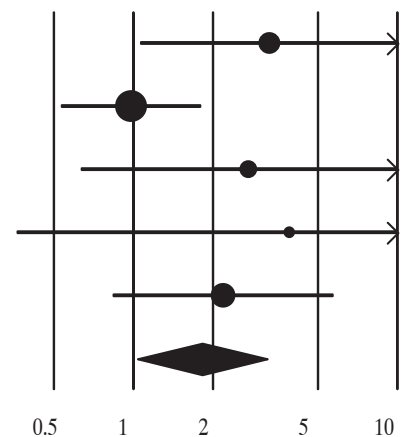

$0.1 \quad 0.2$

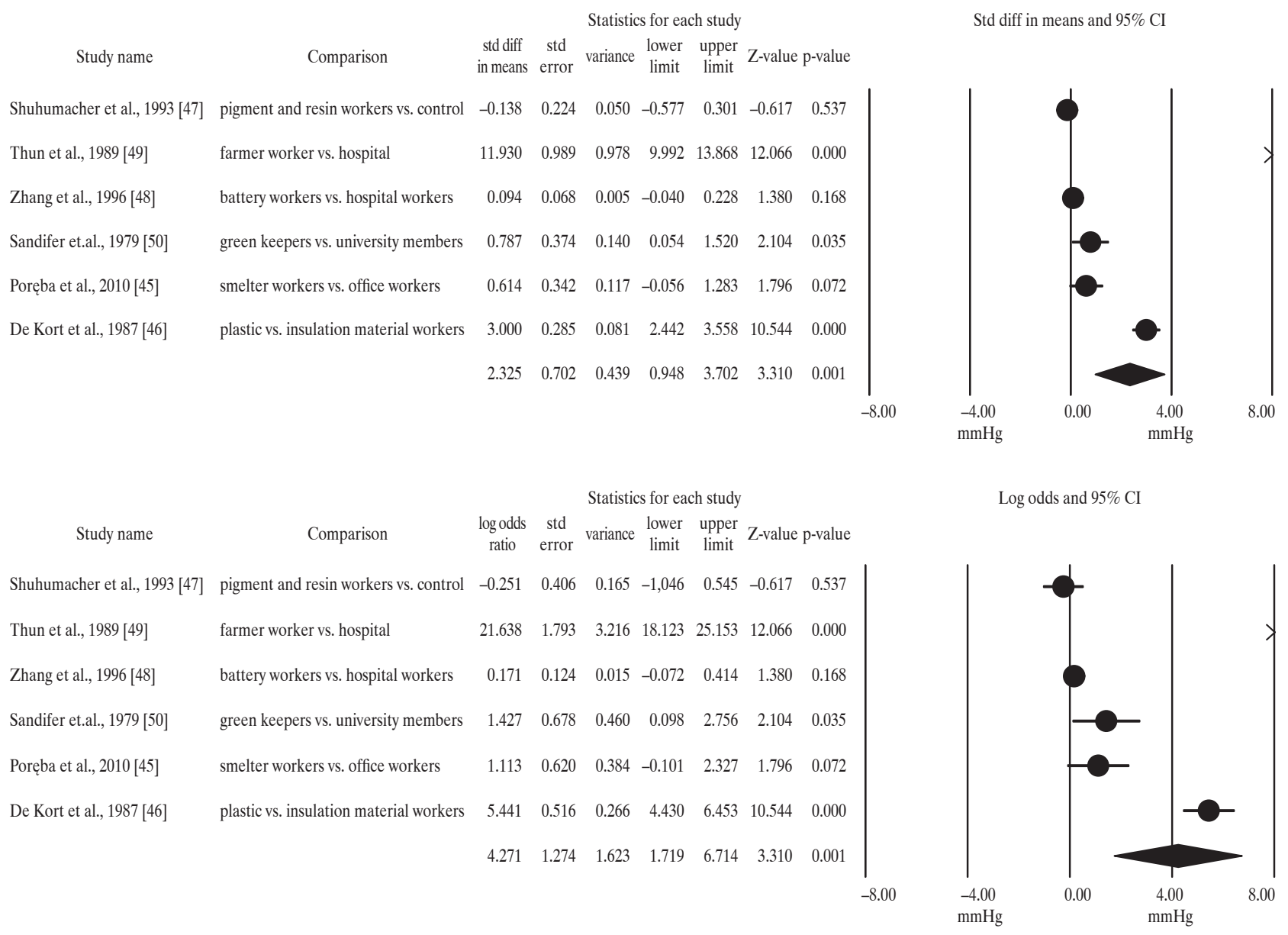

a-standard difference in means.

b - Log odds ratio.

Fig. 3. Forest plot of systolic pressure 


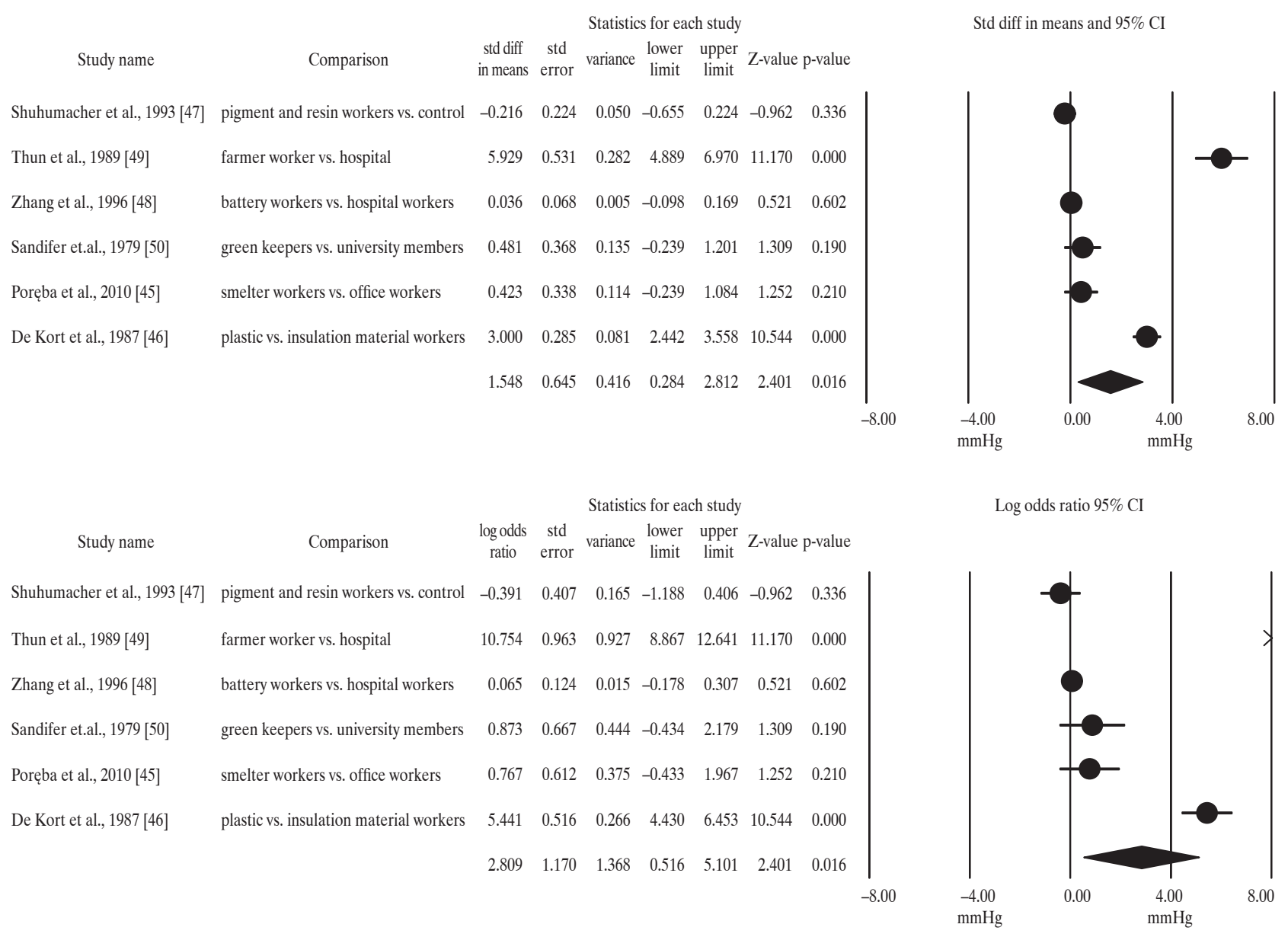

Abbreviations as in Figure 3.

Fig. 4. Forest plot of diastolic pressure

function, salt retention and volume overload [60]: all factors that could cause an increase in blood pressure.

Our study seems to confirm the observations previously expressed in many articles and studies conducted mainly on the general population. In occupationally exposed individuals, cadmium seems to induce an increase in systolic, diastolic and mean blood pressure, and an increase in the prevalence of hypertension.

In particular, a significant increase in systolic arterial pressure was reported in the workers with an ES of 2.325. Less marked, but still valid and statistically significant, is the increase in diastolic blood pressure in the exposed workers with an ES of 1.548. The Logarithmic Odds Ratio values
(Log OR) confirmed and supported these findings, both for systolic blood pressure (4.217), as well as for diastolic blood pressure (2.809).

The prevalence of hypertension was stronger in the exposed individuals, with an OR of 1.825 .

Cadmiuria and cadmiemia are surely excellent indexes of exposure, with an ES of 1.784 and of 2.153 respectively, and with an index of heterogeneity of 13.38 and of 13.06 respectively (Table 2). Both these two markers seem to be useful in the determination of exposure to cadmium, since they play different and complementary roles: cadmiuria is, in fact, an indicator of exposure when it is high and prolonged in time and it is an indicator of accumulation when the exposure is 
modest [61]. Cadmiuria also increases in the presence of cadmium-induced nephropathy [61]. Cadmiemia, on the other hand, is an indicator of recent exposure (2-3 months), and is more sensitive in smokers [62]. Statistically significant increases, both in cadmiuria $(1.12 \pm 0.24 \pm 0.15$ vs. 0.62 $\mu \mathrm{g} / \mathrm{mg}$ creatinine, $\mathrm{p}=0.01)$ [46] $(9.3 \pm 6.9$ vs. $0.7 \pm 0.7 \mu \mathrm{g} / \mathrm{g}$ creatinine, $p<0.0001)$ [49] and in cadmiemia $(1.32 \pm 0.32$ vs. $0.54 \pm 0.17 \mu \mathrm{g} / 1, \mathrm{p}=0.001)$ [46] (7.9 \pm 2.0 vs. $1.2 \pm 2.0 \mu \mathrm{g} / \mathrm{l}$, $\mathrm{p}<0.0001$ ) [49] were reported in the two studies in which the two markers were measured $[46,49]$.

Potential limitations of this study should be obviously sought in the lack of the controlled studies concerning the evaluation of chronic effects on the cardio-circulatory apparatus in the subjects occupationally exposed to cadmium and in the lack of systematic reviews on the topic. The poor number of articles concerning this subject necessitated the inclusion of a study that did not present sufficient data on the levels of cadmium. Nevertheless, the groups analyzed had been strictly selected according to their work history (greenkeepers vs. employees and members of the Faculty of Medicine of South Caroline).

For the same reason, a study that analyzed groups of workers who were exposed to heavy metals including cadmium, manganese and lead, another element known for its capacity to increase blood pressure, was included in the meta analysis. In this study, however, the group of 171 exposed workers was divided into subgroups according to the levels of metal found in their blood. For the meta-analysis, only the subgroup of workers who had blood cadmium levels above the median $(1.93 \mathrm{mg} / \mathrm{l})$ and levels of lead and manganese below the median were selected. In this subgroup the values of ALA-U (urine concentration or delta-Aminolevulenic acid) and FEP-E (protoporpyrin free erythrocyte concentration) were low, showing that the exposure of these subjects to lead and manganese was less relevant.

The heterogeneity shown in the studies is another possible limitation of our study. The $\mathrm{I}^{2}$ turned out to be very high with respect to the "systolic blood pressure" variables ( $\left.\mathrm{I}^{2}: 83.65\right)$.
The heterogeneity probably results from the lack of homogeneity in the number of cases and controls in some of the analyzed studies. Another possible cause of the high heterogeneity found in the "systolic blood pressure" classes is probably the highly significant difference in the number of the studied subjects. The studies involving a greater number of case and control groups could play a more important role in the final statistical analysis than the studies with fewer groups. Adopting the "random" method in the evaluation of SMD, has, however, partially corrected this issue, balancing the weight given to each study. In fact, the index of inconsistency in the analysis of the prevalence of hypertension and in the analysis of cadmiemia was found to be zero ( $\left.\mathrm{I}^{2}: 0.00\right)$. The final, possible limitation of our research is the fact that some of the studies did not include important variables such as smoking status, BMI, cadmiuria and cadmiemia. Therefore, it was not possible to include this data in the statistical analysis and to assess how these variables could have influenced blood pressure in the groups of cases and controls. However, it's possible to imagine how, even a minimal smoking habit may have influenced blood pressure; the case and control groups have in fact similar percentages of smokers. Additionally, it was not possible to operate the stratification based on the values of cadmiuria or cadmiemia, since the analyzed studies did not provide such analyses.

The groups selected for the studies were substantially comparable in terms of age $(42.4 \pm 7.18$ in the cases and $41.77 \pm 5.43$ in the controls), percentage of smokers (57 out of 102 in the cases: $55.88 \%$; 57 out of 91 in the controls: $62.63 \%$ ), and sex. All this contributes to the validity of the study by eliminating potential misleading factors. Another positive aspect is the low standard error reported in the available studies.

Our meta-analysis, therefore, is useful for establishing the role of cadmium in the determination of hypertension in the occupationally exposed subjects. As regards the exact physiopathology of the metal in hypertension induction, there is still a lot to be clarified. 


\section{CONCLUSION}

Cadmium causes a distinct increase in systolic pressure and a more modest increase in diastolic blood pressure in subjects exposed as part of their occupation. Moreover, it causes an increase in the prevalence of hypertension.

Cadmiuria would seem to be an excellent index of chronic exposure to cadmium, while cadmiemia is less reliable for mid-long term exposure.

However, once again, it should be emphasized that cardiovascular disorders associated with exposure to cadmium in the workplace have not been extensively studied. Many studies have been conducted on the general population and the few studies available have different types of limitations such as small control groups. Consequently, it would be advisable to conduct a more extensive case-control study on this topic, also taking into account other cardiovascular parameters such as electrocardiogram - ECG, heart rate, eco-cardiographic parameters and other instrument tests, in order to more carefully analyze the effect of cadmium on cardio-circulatory functions in occupationally-exposed subjects.

\section{REFERENCES}

1. Boonprasert K, Kongjam P, Limpatanachote P, Ruengweerayut R, Na-Bangchang K. Urinary and blood cadmium levels in relation to types of food and water intake and smoking status in a Thai population residing in cadmium-contaminated areas in Mae Sot. Southeast Asian J Trop Med Public Health 2011;42(6):1521-30.

2. Madeddu R, Solinas G, Forte G, Bocca B, Asara Y, Tolu P, et al. Diet and nutrients are contributing factors that influence blood cadmium levels. Nutr Res 2011;31(9):691-7. DOI: 10.1016/j.nutres.2011.09.003.

3. World Health Organization. Guidelines for drinking-water quality [cited 2011 May 12]. Geneva: WHO; 2004. p. 317. Available from URL: http://www.who.int/water_sanitation_ health/dwq/GDWQ2004web.pdf.
4. Friberg L, Kjellström T, Nordberg GF. Cadmium. In: Friberg L, Nordberg GF, Vouk VB, editors. Handbook on the toxicology of metals. Vol. II. 2nd ed. Amsterdam: Elsevier Science Publishers; 1986. p. 355-77.

5. U.S. Environmental Protection Agency. Chemical identification, production and use of cadmium. Washington: EPA; 1999.

6. Chen A, Dietrich KN, Huo X, Ho SM. Developmental neurotoxicants in e-waste: An emerging health concern. Environ Health Perspect 2011;119(4):431-8. DOI: 10.1289/ ehp.1002452. Epub 2010 Oct 20.

7. Wojtczak-Jaroszowa J, Kubow S. Carbon monoxide, carbon disulfide, lead and cadmium - four examples of occupational toxic agents linked to cardiovascular disease. Med Hypotheses 1989;30(2):141-50.

8. Navas-Acien A, Selvin E, Sharrett AR, Calderon-Aranda E, Silbergeld E, Guallar E. Lead, cadmium, smoking, and increased risk of peripheral arterial disease. Circulation 2004;109(25):3196-201.

9. Peters JL, Perlstein TS, Perry MJ, McNeely E, Weuve J. Cadmium exposure in association with history of stroke and heart failure. Environ Res 2010;110(2):199-206.

10. Everett CJ, Frithsen IL. Association of urinary cadmium and myocardial infarction. Environ Res 2008;106(2):284-6.

11. Swaddiwudhipong W, Mahasakpan P, Limpatanachote P, Krintratun S. Correlations of urinary cadmium with ipertension and diabetes in persons living in cadmium-contaminated villages in north western Thailand: A population study. Environ Res 2010;110(6):612-6.

12. Messner B, Knoflach M, Seubert A, Ritsch A, Pfaller K, Henderson B, et al. Cadmium is a novel and independent risk factor for early atherosclerosis mechanisms and in vivo relevance. Arterioscler Thromb Vasc Biol 2009;29(9):1392-8.

13. Schutte R, Nawrot T, Richart T, Thijs L, Roels HA, van Bortel LM, et al. Arterial structure and function and environmental exposure to cadmium. Occup Environ Med 2008;65(6):412-9.

14. Hermann U, Kaulich TW, Schweinsberg F. Correlation of blood pressure and cadmium and lead content of the hair in 
nonsmoking males. Zentralbl Hyg Umweltmed 1989;188 (3-4):240-53 [in German].

15. Kuliczkowski W, Jołda-Mydłowska B, Kobusiak-Prokopowicz M, Antonowicz-Juchniewicz J, Kosmala W. Effect of heavy metal ions on function of vascular endothelium in patients with ischemic heart disease. Pol Arch Med Wewn 2004;111(6):679-85 [in Polish].

16. Lee MS, Park SK, Hu H, Lee S. Cadmium exposure and cardiovascular disease in the 2005 Korea National Health and Nutrition Examination Survey. Environ Res 2011;111(1):171-6.

17. Lin JL, Lu FH, Yeh KH. Increased body cadmium burden in Chinese women without smoking and occupational exposure. J Toxicol Clin Toxicol 1995;33(6):639-44.

18. Afridi HI, Kazi TG, Kazi GH, Jamali MK, Shar GQ. Essential trace and toxic element distribution in the scalp hair of Pakistani myocardial infarction patients and controls. Biol Trace Elem Res 2006;113(1):19-34.

19. Tang YR, Zhang SQ, Xiong Y, Zhao Y, Fu H, Zhang H-P, et al. Studies of five microelement contents in human serum, hair, and fingernails correlated with aged hypertension and coronary heart disease. Biol Trace Elem Res 2003;92(2):97-104.

20. Kopp SJ, Glonek T, Erlanger M, Perry EF, Perry HM Jr, Bárány M. Cadmium and lead effects on myocardial function and metabolism. J Environ Pathol Toxicol 1980;4(2-3): 205-27.

21. Schroeder HA, Vinton WH Jr. Hypertension induced in rats by small doses of cadmium. Am J Physiol 1962;202:515-8.

22. Subramanyam G, Bhaskar M, Govindappa S. The role of cadmium in induction of atherosclerosis in rabbits. Indian Heart J 1992;44(3):177-80.

23. Bhatnagar A. Environmental cardiology: studying mechanistic links between pollution and heart disease. Circ Res 2006;29(7):692-705.

24. Prozialeck WC, Edwards JR, Woods JM. The vascular endothelium as a target of cadmium toxicity. Life Sci 2006;79(16):1493-506.

25. Zikić RV, Stajn AS, Ognjanović BI, Saicić ZS, Kostić MM, Pavlovic SZ, et al. The effect of cadmium and selenium on the antioxidant enzyme activities in rat heart. J Environ Pathol Toxicol Oncol 1998;17(3-4):259-64.

26. Kisling GM, Kopp SJ, Paulson DJ, Tow JP. Cadmiuminduced attenuation of coronary blood flow in the perfused rat heart. Toxicol Appl Pharmacol 1993;118(1):58-64.

27. Wang Y, Fang J, Leonard SS, Rao KM. Cadmium inhibits the electron transfer chain and induces reactive oxygen species. Free Radic Biol Med 2004;36(11):1434-43.

28. Gerhardsson L, Brune D, Nordberg GF, Wester PO. Multielemental assay of tissues of deceased smelter workers and controls. Sci Total Environ 1988;74:97-110.

29. Sorahan T, Lister A, Gilthorpe MS, Harrington JM. Mortality of copper cadmium alloy workers with special reference to lung cancer and non-malignant disease of the respiratory system. Occup Environ Med 1995;52(12):804-12.

30. Armstrong BG, Kazantzis G. The mortality of cadmium workers. Lancet 1983;1(8339):1425-7.

31. Greenberg A, Parkinson DK, Fetterolf DE, Puschett JB, Ellis $\mathrm{KJ}$, Wielopolski L, et al. Effects of elevated lead and cadmium burdens on renal function and calcium metabolism. Arch Environ Health 1986;41(2):69-76.

32. De Kort WL, Zwennis WC. Blood lead and blood pressure: some implications for the situation in The Netherlands. Environ Health Perspect 1988;78:67-70.

33. Lauwerys R, Amery A, Bernard A, Bruaux P, Buchet J-P, Claeys F, et al. Health effects of environmental exposure to cadmium: objectives, design and organization of the Cadmibel Study: A cross-sectional morbidity study carried out in Belgium from 1985 to 1989. Environ Health Perspect 1990;87:283-9.

34. Sancini A, Tomei G, Vitarelli A, Caciari T, Samperi I, Pacchiarotti A, et al. Cardiovascular risk in rotogravure industry. J Occup Environ Med 2012;54(5):551-7.

35. Ciarrocca M, Tomei F, Caciari T, Cetica C, Andrè JC, Fiaschetti $\mathrm{M}$, et al. Exposure to arsenic in urban and rural areas and effects on thyroid hormones. Inhal Toxicol 2012;24(9):589-98. 36. Sancini A, Tomei F, Tomei G, Caciari T, di Giorgio V, André JC, et al. Urban pollution. G Ital Med Lav Ergon 2012;34(2):187-96. 
37. Caciari T, Sancini A, Tomei F, Antetomaso L, Tomei G, Scala B, et al. Cadmium blood/urine levels and blood pressure in workers occupationally exposed to urban stressor. Ann Ig 2012;24(5):417-28.

38. Ciarrocca M, Capozzella A, Tomei F, Tomei G, Caciari T. Exposure to cadmium in male urban and rural workers and effects on FSH, LH and testosterone. Chemosphere 2013;90(7):2077-84. DOI: 10.1016/j.chemosphere.2012.10.060. Epub 2013 Jan 3.

39. Sancini A, Caciari T, di Pastena C, Sinibaldi F, Scala B, Fiaschetti M, et al. Meta-analysis: cardiovascular effects in workers occupationally exposed to urban pollution. Prev Res 2011;1(1):87-100 [in Italian].

40. Engvall J, Perk J. Prevalence of hypertension among cadmium-exposed workers. Arch Environ Health 1985;40(3): $185-90$.

41. Zerbino DD, Solomenchuk TN. Myocardial infarction at the age under 50: influence of occupational xenobiotics (analysis of chemical elements in hair of patients). Med Tr Prom Ekol 2007;2:17-21 [in Russian].

42. Sroczyński J, Biskupek K, Piotrowski J, Rudzki H. Effect of occupational exposure to lead, zinc and cadmium on various indicators of the circulatory system of metallurgical workers. Med Pr 1990;41(3):152-8 [in Polish].

43. Mehra R, Juneja M. Hair as an indicator for assessing adverse effect of cadmium on human health. J Environ Sci Eng 2005;47(1):59-64.

44. Vorobeeva RS, Eremeeva EP. Cardiovascular function in workers exposed to cadmium. Gig Sanit 1980;10:22-25 [in Russian].

45. Poręba R, Gać P, Poręba M, Derkacz A, Pilecki W, Antonowicz-Juchniewicz J, et al. Relation between chronic exposure to lead, cadmium, and manganese, blood pressure values and incidence of arterial hypertension. Med Pr 2010;61(1):5-14 [in Polish].

46. De Kort WL, Verschoor MA, Wibowo AA, van Hemmen JJ. Occupational exposure to lead and blood pressure: A study in 105 workers. Am J Ind Med 1987;11(2):145-56.
47. Schuhmacher M, Bosque MA, Domingo JL, Corbella J. Effects of chronic lead and cadmium exposure on blood pressure in occupationally exposed workers. Biol Trace Elem Res 1994;41(3):269-78.

48. Zhang G, Li X, Guo B, Tian G. A Survey of blood pressure in cadmium-exposed workers. J Occup Health 1996;38: 198-200.

49. Thun MJ, Osorio AM, Schober S, Hannon WH, Lewis B, Halperin W. Nephropathy in cadmium workers: assessment of risk from airborne occupational exposure to cadmium. $\mathrm{Br}$ J Ind Med 1989;46(10):689-97.

50. Sandifer SH, Wilkins RT, Whitlock NH, Virella G, Loadholt CB, Leitner TC. Urinary protein excretion in workers exposed to low doses of cadmium. Bull Environ Contam Toxicol 1979;23(1-2):129-35.

51. World Health Organization. The WHO/ISH cardiovascular risk prediction charts. In: Prevention of cardiovascular disease: guideline for assessment and management of cardiovascular risk [cited 2011 May 12]. Geneva: WHO; 2007. Available from URL: http://www.who.int/cardiovascular_diseases/ guidelines/Full\%20text.pdf.

52. Friberg L. Health hazards in the manifacture of alkaline accumulators with special reference to chronic cadmium poisoning; a clinical and experimental study. Acta Med Scand Suppl 1950;240:1-124.

53. Schroeder HA, Nason AP, Tipton IH, Balassa JJ. Essential trace metals in man: zinc. Relation to environmental cadmium. J Chronic Dis 1967;20(4):179-210.

54. Houston MC. The role of mercury and cadmium heavy metals in vascular disease, hypertension, coronary heart disease, and myocardial infarction. Altern Ther Health Med 2007;13(2):S128-33.

55. Gökalp O, Ozdem S, Dönmez S, Dogan M, Demirin H, Kara HY, et al. Impairment of endothelium-dependent vasorelaxation in cadmium-hypertensive rats. Toxicol Ind Health 2009;25(7):447-53.

56. Suwalsky M, Norris B, Cárdenas H. Effects of cadmium on $\mathrm{Na}+$ transport in the isolated skin of the toad Pleurodema thaul. J Inorg Biochem 2005;99(12):2362-71. 
57. Bilgen I, Oner G, Edremitlioglu M, Alkan Z, Cirrik S. Involvement of cholinoceptors in cadmium-induced endothelial dysfunction. J Basic Clin Physiol Pharmacol 2003;14(1):55-76.

58. Knoflach M, Kiechl S, Penz D, Zangerle A, Schmidauer C, Rossmann A, et al. Cardiovascular risk factors and atherosclerosis in young women: atherosclerosis risk factors in female youngsters (ARFY study). Stroke 2009;40(4):1063-9.

59. Tomera JF, Lilford K, Kukulka SP, Friend KD, Harakal C. Divalent cations in hypertension with implications to heart disease: calcium, cadmium interactions. Methods Find Exp Clin Pharmacol 1994;16(2):97-107.
60. Satarug S, Nishijo M, Ujjin P, Vanavanitkun Y, Moore MR. Cadmium-induced nephropathy in the development of high blood pressure. Toxicol Lett 2005;157(1):57-68.

61. Campurra G. Cadmio - leghe e composti. Handbook of occupational medicine. Milan: Wolters Kluwer Italia; 2008. p. 787 [in Italian].

62. Cikrt M, Tichý M, Bláha K, Bittnerová D, Havrdová J, Lepsi $\mathrm{P}$, et al. The study of exposure to cadmium in the general population. II. Morbidity studies. Pol J Occup Med Environ Health 1992;5(4):345-56.

This work is available in Open Access model and licensed under a Creative Commons Attribution-NonCommercial 3.0 Poland License - http://creativecommons.org/ licenses/by-nc/3.0/pl/deed.en. 